\title{
Peperomia ciliato-caespitosa M. Carvalho-Silva \& E.F. Guim. (Piperaceae): uma nova espécie para o Brasil ${ }^{1}$
}

\author{
Micheline Carvalho-Silva ${ }^{2,3}$ e Elsie Franklin Guimarães ${ }^{2}$
}

Recebido em 26/02/2007. Aceito em 13/08/2007

\begin{abstract}
RESUMO - (Peperomia ciliato-caespitosa M. Carvalho-Silva \& E.F. Guim. (Piperaceae): uma nova espécie para o Brasil). Os estudos taxonômicos que se vem realizando com as Piperaceae para o Brasil permitiram acrescentar uma nova espécie para a família com base em material analisado do Estado do Espírito Santo. Peperomia ciliato-caespitosa é uma planta que ocorre em campos rupestres, apresentando hábito cespitoso e frutos peculiares, que a enquadram no subgênero Rhynchophorum (Miq.) Dahlst. O novo táxon é descrito, ilustrado e comparado com os afins.
\end{abstract}

Palavras-chave: Peperomia, Piperaceae, flora do Brasil, nova espécie

ABSTRACT - (Peperomia ciliato-caespitosa M. Carvalho-Silva \& E.F. Guim. (Piperaceae): a new species from Brazil). Taxonomic studies on the Piperaceae in Brazil revealed a new species for the family, based on material from Espirito Santo state. Peperomia ciliatocaespitosa is a plant that occurs in "campos rupestres" with a cespitose habit and characteristic fruits, belonging to the subgenus Rhynchophorum (Miq.) Dahlst. The new taxon is described, illustrated and compared to related species.

Key words: Peperomia, Piperaceae, Brazilian flora, new species

\section{Introdução}

As Peperomia estão representadas no Brasil por cerca de 170 espécies que habitam, principalmente, as matas ombrófilas e, menos freqüentemente, as matas secas, os campos rupestres e os campos úmidos. São ervas epífitas ou terrestres, com folhas geralmente carnosas, de disposição alterna, oposta ou verticilada, com inflorescências em espigas ou racemos e flores com dois estames (Miquel 1843; Dahlstedt 1900; Yuncker 1974).

O gênero está dividido em cinco subgêneros para o Brasil, diferenciados pela forma dos frutos. São eles: Acrocarpidium (Miq.) Dahlst., Tildenia (Miq.) Dahlst., Micropier (Miq.) Dahlst., Sphaerocarpidium Dahlst., Rhynchophorum (Miq.) Dahlst. (Yuncker 1974). Trabalhos sobre novas espécies, combinações e sinonimizações vem sendo, recentemente, desenvolvidos, assim como floras regionais (CarvalhoSilva \& Cavalcanti 2002; Guimarães \& Monteiro 2006).

\section{Descrição e discussão}

Peperomia ciliato-caespitosa M. Carvalho-Silva \& E.F. Guim. sp. nov.

Fig. 1-17

Herba rupicola, caespitosa, $15-40 \mathrm{~cm}$ alta; rami glabri, exfoliantes. Folia opposita, obovato-elliptica ad abovata, coriacea, discoloria, glabra, glandulis flavescentibus instructa; lamina $2-2,5 \mathrm{~cm}$ longa et 1,5-2 cm lata, apice obtuso, mucrone brevi, margine plano, profuse ciliato, base obtusa, interdum brevipeltata; petiolus $0,4-0,7 \mathrm{~cm}$ longus. Inflorescentiae spiciformes, 5,5-6 cm longae, simplices, solitariae, terminales, erectae; pedunculus glaber, pedunculo proximali 1,5-1,7 cm longo, pedunculo distali $1-1,3 \mathrm{~cm}$ longo, 1-bracteato; rhachis 3-3,2 cm longa, glabra; bractea floralis 0,5-0,6 mm diâm., glandulosa. Fructus $1,5 \times 1 \mathrm{~mm}$, ovalis, apice truncato, planus, stigma centrale.

Erva rupícola, cespitosa, $15-40 \mathrm{~cm}$ alt.; ramos glabros, carnosos, esfoliantes quando material

\footnotetext{
1 Parte da Tese de Doutorado da primeira Autora

2 Instituto de Pesquisas Jardim Botânico Rio de Janeiro, Escola Nacional de Botânica Tropical, Rua Pacheco Leão 915, 22460-030 Rio de Janeiro, RJ, Brasil

3 Autor para correspondência: silvamicheline@gmail.com
} 


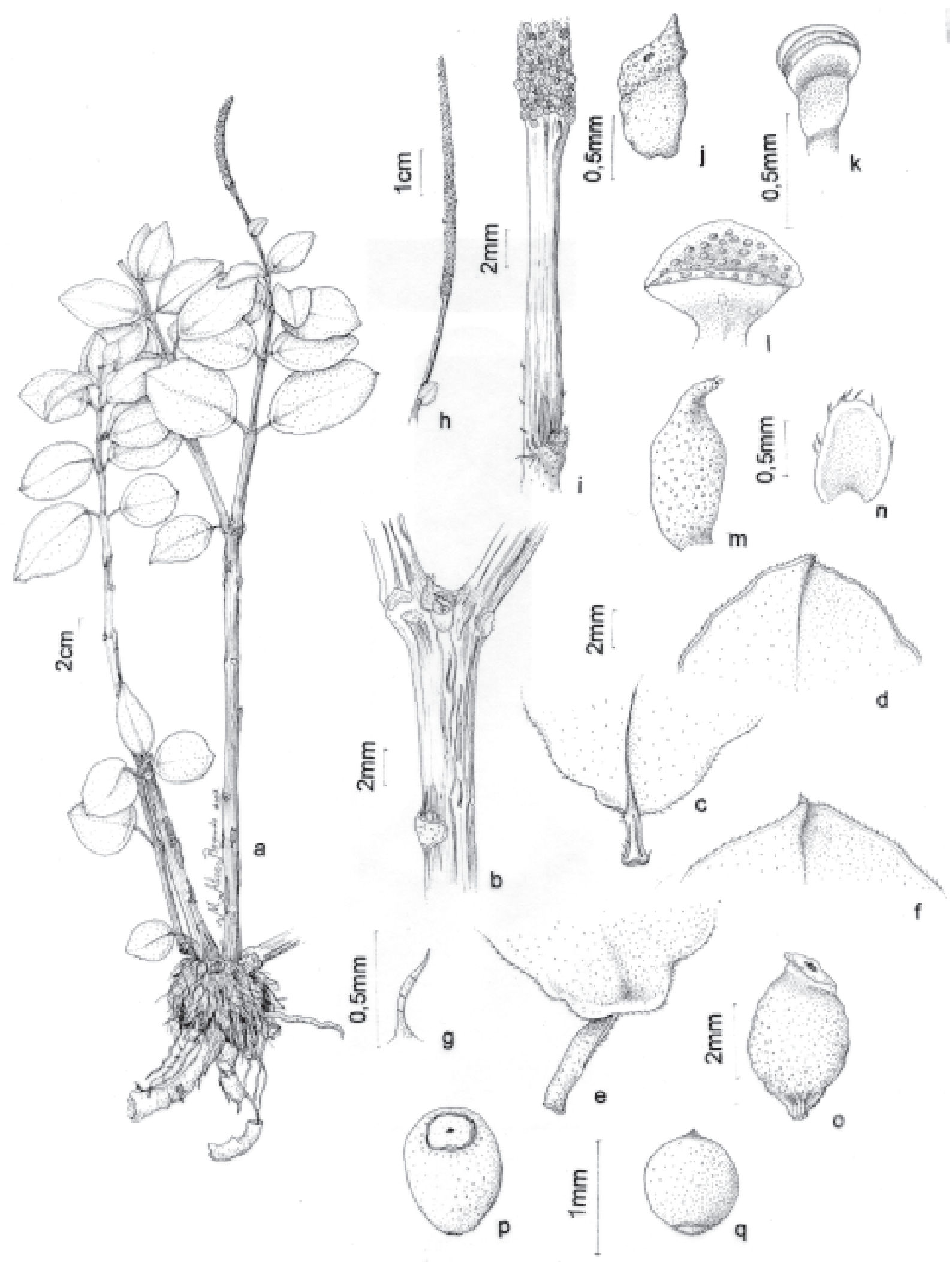

Figuras 1-17. Peperomia ciliato-caespitosa M. Carvalho-Silva \& E.F. Guim. 1. Hábito. 2. Detalhe do ramo com cicatrizes foliares. 3. Base foliar, vista da face abaxial. 4. Ápice foliar, vista da face abaxial. 5. Base foliar peltada, vista da face adaxial. 6. Ápice foliar, vista da face adaxial. 7. Tricoma multicelular. 8. Espiga. 9. Pedúnculo com cicatriz de bráctea peduncular. 10. Ovário. 11. Estame. 12. Bráctea floral. 13. Gema. 14. Bráctea peduncular. 15. Fruto maduro. 16. Visão apical do fruto desprovido do ápice. 17. Semente (Demurer et al. 1342). 
herborizado, ascendentes, eretos, 1,5 mm diâm., entrenós 1,7-2,8 mm compr. Folhas opostas; lâmina 2-2,5×1,5-2 cm, obovado-elíptica a obovada, coriácea, discolor, glabra, às vezes com presença de pequenas glândulas amareladas, hifódroma; ápice obtuso, às vezes com curto mucro, margem plana, profusamente ciliada, tricomas curvados em direção ao ápice, base obtusa, às vezes curto peltada, pelta $0,5-1 \mathrm{~mm}$; pecíolo 0,4-0,7 cm, canaliculado, com tricomas eretos a patentes nas margens do sulco; nervura central inconspícua na face adaxial, proeminente na face abaxial, principalmente próximo a base, secundárias inconspícuas. Inflorescências em espigas, na floração esverdeadas, na frutificação 5,5-6 cm compr., verdes a castanhas, simples, solitárias, terminais, eretas; pedúnculo glabro, o proximal 1,5-1,7 cm compr., o distal 1-1,3 cm compr., 1-bracteado, bráctea peduncular caduca, foliácea, 0,5-0,7 mm compr.; raque $3-3,2 \mathrm{~cm}$ compr., carnosa, glabra, foveolada, fóvea $0,7-1 \times$ $0,3 \mathrm{~mm}$, losangular, bordas crassas e poucas glândulas amarelas; bráctea floral 0,5-0,6 mm diâm., orbicular, peltada, coberta por glândulas amarelas. Ovário glanduloso, principalmente no ápice, incluso na fóvea, exceto o ápice, estigma central. Fruto $1,5 \times 1 \mathrm{~mm}$, elipsóide a ovóide, formando ângulo de $45-60^{\circ} \mathrm{com}$ a raque, ápice truncado, plano, estigma central, quando maduro perde o ápice e a semente fica aparente. Semente globosa, perisperma carnoso.

Tipo: BRASIL. Espírito Santo: Mun. Santa Teresa, São João de Petrópolis, cachoeira do Struts, 3/VIII/2000, fl. fr., V. Demurer et al. 1342 (HolótipoMBML, isótipo-RB).

O estudo das Piperaceae no Brasil favoreceu o acesso a coleções dos diferentes herbários brasileiros e estrangeiros. Quando da visita ao herbário do Museu Biológico Melo Leitão (MBML), analisou-se o exemplar V. Demurer et al. 1342, diagnosticando-o como uma nova espécie para o Estado do Espírito Santo.

Peperomia ciliato-caespitosa M. Carvalho-Silva \& E.F. Guim. possui os frutos ovóides com ápice truncado, plano, enquadrando-a no subgênero Rhynchophorum. As espécies deste subgênero, encontradas no Brasil, até o momento, possuem hábito estolonífero e folhas alternas. No entanto, Peperomia ciliato-caespitosa é uma erva cespitosa, com ramos esfoliantes e folhas sempre opostas, características incomuns no subgênero. A forma e a pilosidade nas folhas podem, à primeira vista, confundi-la com Peperomia incana (Haw.) Hooker, do mesmo subgênero, mas além das diferenças já mencionadas acima, esta última se distingue por apresentar toda a folha e os ramos vilosos, incanos e argênteos. Outra espécie que pode ser confundida, quando estéril, é Peperomia cordigera Dahlst., que difere por apresentar os ramos e folhas densamente pilosos, enquanto $P$. ciliato-caespitosa apresenta estas estruturas glabras.

O epíteto específico refere-se à característica do hábito associada à margem ciliada das folhas.

\section{Agradecimentos}

Ao Conselho Nacional de Desenvolvimento Científico e Tecnológico e à Coordenação de Aperfeiçoamento de Pessoal de Nível Superior, CAPES, CNPq, pelas bolsas concedidas às autoras; à Petrobrás (proc. 610.4.025.02.3 ), Programa Mata Atlântica - JBRJ; aos curadores de herbário pelos materiais remetidos; ao Dr. Tarciso Filgueiras, pela correção da diagnose latina; à Maria Alice Rezende pela ilustração.

\section{Referências bibliográficas}

Carvalho-Silva, M. \& Cavalcanti, T.B. 2002. Piperaceae Pp.93-124. In: T.B. Cavalcanti \& A.E. Ramos (orgs.). Flora do Distrito Federal, Brasil. v.2. Brasília, Embrapa Recursos Genéticos e Biotecnologia.

Dahlstedt, H. 1900. Studien über süd-und central Amerikanishe Peperomien. Svenska VetnskapsAkademiens Handlingar 33: 1-218.

Guimarães, E.F. \& Monteiro, D. 2006. Piperaceae na Reserva Biológica de Poço das Antas, Silva Jardim, Rio de Janeiro, Brasil. Rodriguésia 57: 569-589.

Miquel, F.A.W. 1843. Systema Piperacearum. Rotterdam, Kramers.

Yuncker, T.G. 1974. The Piperaceae of Brazil-III: Peperomia; taxa of uncertain status. Hoehnea 4: 71-413. 